\title{
OS CONTEÚDOS PARA O ENSINO DE MÚSICA E CANTO ORFEÔNICO NA ESCOLA SECUNDÁRA BRASILEIRA (1931-1946)
}

DOI: http://dx.doi.org/10.1590/2236-3459/70749

\author{
Wilson Lemos Júnior \\ Instituto Federal do Paraná (IFPR), Curitiba/Paraná, Brasil
}

$\cos 80$

\begin{abstract}
Resumo
Este artigo investiga os conteúdos adotados no ensino de música e canto orfeônico na Escola Secundária Curitibana durante as décadas de 1930 e 1940. Conforme as análises feitas por Chervel (1990), os conteúdos abordados serão analisados sob duas vertentes, uma sob a ótica legal, revelado pelas leis e decretos de ensino, e outra sob o viés do cotidiano escolar, neste caso, por meio das avaliações encontradas no Colégio Estadual do Paraná nos anos de 1946 e 1947. O artigo está dividido em duas partes. A primeira é dedicada aos conteúdos de música e canto orfeônico a partir da reforma de Francisco Campos, em 1931, e a segunda, é dedicada a partir do ano de 1946, quando por orientação do ministro Raul Leitão da Cunha, o programa da disciplina foi reformulado.

Palavras-chave: história da educação, arte-educação, educação musical.
\end{abstract}

\section{THE CONTENT FOR MUSIC EDUCATION AND ORPHEONIC SINGING IN THE BRAZILIAN SECONDARY SCHOOL}

\begin{abstract}
This article investigates the contents adopted in the teaching of music and orpheonic singing in the secondary school of Curitiba during the 1930s and 1940s. According to the analyzes made by Chervel (1990), the contents will be analyzed in two aspects, one under the legal optics, revealed by laws and educational decrees, and another on the school reality, in this case, through the assessments found in the Colégio Estadual do Paraná in the years 1946 and 1947. The article is divided into two parts. The first is dedicated to the contents of music education in the reform of Francisco Campos in 1931, and the second is dedicated to the period after 1946, when the course program was redesigned, under the guidance of the minister Raul Leitão da Cunha. Keywords: history of education, art-education, music education.
\end{abstract}

\section{LOS CONTENIDOS PARA LA EDUCACIÓN MUSICAL EN ESCUELA SECUNDARIA DE BRASIL}

\section{Resumen}

Este artículo investiga el contenido adoptados en la enseñanza de la música y el canto coral en Curitiba escuela secundaria durante los años 1930 y 1940. De acuerdo con el análisis realizado por Chervel (1990), el contenido se puede analizar desde dos puntos de vista, uno desde un punto de vista jurídico, puesto de manifiesto por la leyes y decretos enseñanza, y otro sobre la realidad escolar, en este caso, a través de las evaluaciones que se encuentran en el Colégio Estadual do Paraná en 1946 y 1947. El artículo se divide en dos partes. La primera está dedicada a los contenidos de música y canto coral en la reforma de Francisco Campos en 1931, y la segunda está dedicada al período posterior a 1946, cuando el programa del curso fue 
reformulado, bajo la dirección del ministro Raul Leitão da Cunha.

Palabras clave: historia de la educación, educación artística, educación musical.

\section{LE CONTENU DE LA MUSIQUE À L'ÉCOLE SECONDAIRE BRÉSILIEN}

\section{Résumé}

Cet article examine le contenu adoptés dans l'enseignement de la musique et le chant choral à Curitiba école secondaire au cours des années 1930 et 1940. Selon l'analyse par Chervel (1990), le contenu sera analysée sous deux angles, l'un d'un point de vue juridique, révélé par les lois et décrets d'enseignement, et un autre sous la réalité de l'école, dans ce cas, à travers les évaluations trouvées dans le Colégio Estadual do Paraná en 1946 et 1947. L'article est divisé en deux parties. Le premier est dédié au contenu de l'éducation musicale dans la réforme de Francisco Campos en 1931, et le second est dédié à partir de 1946, lorsque le programme de cours a été reformule, par le ministre Raul Leitão da Cunha.

Mots-clés: histoire de l'éducation, éducation artistique, l'éducation musicale. 


\title{
Introdução
}

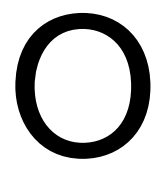

s conteúdos assumem uma grande importância para um trabalho que privilegia a história de uma disciplina, uma vez que estes não são escolhidos ao acaso, revelando uma íntima relação com o aspecto político e social de uma época. Neste sentido, este artigo pretende contribuir para a compreensão dos conteúdos privilegiados no ensino de música e canto orfeônico na escola secundária curitibana durante as décadas de 1930 e 1940.

Conforme as análises feitas por André Chervel (1990), os conteúdos abordados serão analisados sob duas vertentes, uma sob a ótica legal, revelado pelas leis e decretos de ensino, e outra sob o viés do cotidiano escolar, neste caso, por meio das avaliações encontradas no Colégio Estadual do Paraná ${ }^{1}$ para os anos de 1946 e 1947. O período proposto passa por dois momentos, um a partir de 1931, quando a disciplina é inserida oficialmente no currículo das escolas secundárias, e outro a partir de 1946, quando a disciplina passa por uma reforma, que alterou o programa e inseriu a avaliação obrigatória para a disciplina de canto orfeônico.

Busca-se investigar questões pertinentes sobre o conteúdo de canto orfeônico como: qual a viabilidade do conteúdo prescrito para a prática no cotidiano escolar? Quais as diferenças entre o conteúdo adotado na legislação de 1931 daquele adotado em 1946? Quais as relações entre os conteúdos adotados na lei com àqueles aplicados na escola?

Como fontes, além da legislação em vigor, são utilizados livros didáticos e atas de provas catalogadas no Colégio Estadual do Paraná a partir do ano de 1946, ano em que foi incluída a obrigatoriedade da avaliação formal para o ensino de música e canto orfeônico².

$\mathrm{O}$ artigo está dividido em duas partes. A primeira é dedicada aos conteúdos de música e canto orfeônico a partir da reforma de Francisco Campos, em 1931, quando foi publicado o programa oficial da disciplina. A segunda parte, dedica-se a partir do ano de 1946, quando por orientação do ministro Raul Leitão da Cunha, o programa da disciplina é reformulado.

\section{Os conteúdos de música e canto orfeônico a partir da reforma de 1931}

$\mathrm{Na}$ reforma de 1931, proposta pelo Ministro Francisco Campos, o programa de música e canto orfeônico apresentava-se disposto da seguinte maneira no Decreto-lei 19.890, de 18 de abril de 1931:

\author{
PRIMEIRA SÉRIE \\ (2 HORAS) \\ I. Canto e solfejo
}

\footnotetext{
${ }^{1}$ Até 1942, a instituição levava o nome de Ginásio Paranaense. Em 1943, seu nome foi alterado de Ginásio Paranaense para Colégio Paranaense. Ainda em 1943, aconteceu outra alteração, passando para Colégio Estadual do Paraná, que é a atual nomenclatura.

2 Atualmente, há uma grande quantidade de trabalhos que abordam o ensino do Canto Orfeônico em diferentes contextos. Autores como Contier (1998), Fonterrada (2008), Fuks (1991), Gilioli (2008) e Loureiro (2003), tratam da história, expansão e análises metodológicas a respeito do ensino do Canto Orfeônico no Brasil. Há ainda algumas teses e dissertações que abordam o assunto como é o caso da dissertação de Gilioli (2003) que foca o ensino de Canto Orfeônico no estado de São Paulo durante a Primeira República e da tese de Galinari (2007) que faz uma análise do discurso do Canto Orfeônico no Brasil durante a Era Vargas.
} 
a) Canto: No início o canto está em uníssono. A respiração, a emissão vocal e o ritmo deverão constituir objetivos de cuidadosa instrução.

Conhecidas aptidões particularidades dos alunos e, ao fim de certo tempo, preparam-se gradativamente elementos para o canto coral a duas vozes, sempre de acordo com a tessitura da voz na adolescência.

Cantos obrigatórios: Hino Nacional, Hino à Bandeira e outros hinos patrióticos.

b) Solfejo: Desenvolvimento da leitura musical, coordenada com aulas teóricas iniciais.

II. Teoria musical

Elementos indispensáveis para ler e interpretar a notação musical de composição muito simples:

1. Definições gerais; notas; pautas; claves.

2. Valores e pausas.

3. Compassos e tempos.

4. Sinais de aumento e diminuição.

5. Intervalos.

6. Alterações.

O ensino teórico só será ministrado quando a classe houver adquirido gosto pelo canto coral. As aulas sistemáticas de teoria deverão recapitular, coordenar e completar as noções que forem aprendidas gradualmente, deduzindo-as do canto coral e da audição fonográfica.

III. Audição fonográfica.

a) Reprodução fonográfica de trechos de boa música.

Far-se-á a análise dos valores estéticos dos trechos ouvidos, suscitando-se dos alunos a impressão das emoções recebidas.

b) Grandes períodos da História da Música: Época clássica.

Fatos relativos á época e á vida dos compositores; características das obras ouvidas.

Os trechos serão repetidos várias vezes, procurando-se fixa-los na memória dos alunos.

\section{SEGUNDA SÉRIE}

(2 HORAS)

I. Canto e solfejo.

a) Canto: Desenvolvimento do canto a 2 vozes, observadas sempre as tessituras. Preparo inicial dos corais a três vozes, de acordo com as regras gerais expostas no programa da 1aㅡ série.

Cantos obrigatórios: Hinos patrióticos, Hino das nações que tem relações freqüentes com o Brasil. Canções regionais e tradicionais, brasileiras e estrangeiras.

b) Solfejo: Desenvolvimento da leitura à primeira vista, a uma e a duas vozes, aplicando-se os conhecimentos adquiridos anteriormente.

II. Teoria musical

1. Compassos compostos e mistos.

2. Anotamentos e metrônomo.

3. Sinais de expressão e colorido.

4. Síncope e contratempo.

5. Quiálteras e ornamentos.

6. Tonalidades. Modos. Armaduras de claves.

As noções teóricas serão deduzidas, quanto possíveis, do canto e da audição fonográfica.

III. Audição fonográfica.

a) Repertório sinfônico e lírico.

b) Grandes períodos da História da Música: Época romântica.

Observar as diretrizes expostas no programa da $1^{\text {a }}$ série.

TERCEIRA SÉRIE

(1 HORA) 
I. Canto e solfejo

a) Canto: Desenvolvimento dos córos a três vozes.

Cantos obrigatórios: Hinos patrióticos e cívicos. Hinos nacionais e estrangeiros.

Canções regionais e tradicionais, brasileiras e estrangeiras.

b) Solfejo a três vozes, preparado e á primeira vista.

c) Pequenos ditados fáceis, de quatro ou oito compassos.

II. Teoria musical.

1. Noções e acordes de três a quatro sons. Inversões.

2. Voz humana: Classificação e claves respectivas.

3. Noções sucintas de tecnologia musical afim de habilitar o aluno a compreender o vocabulário referente á música de câmara, sinconcertos ou representações teatrais.

Os exemplos serão sempre deduzidos do canto e da audição fonográfica.

\section{Audição fonográfica}

a) Repertório de música de câmara.

b) Grandes períodos da História da Música: Época contemporânea e moderna.

Observar as diretrizes no programa da $1^{1}$ série.

(BRASIL, 1931).

O programa da disciplina de música no ensino ginasial apresenta uma síntese dos pontos básicos para uma formação de caráter erudita ${ }^{3}$. Existe uma forte preocupação no ensino da teoria musical, presente nos três anos de maneira progressiva, assim como no conteúdo histórico da música erudita: o Clássico, representado por Wolfgang Amadeus Mozart, que ficou conhecido como estilo acadêmico, pois a composição musical seguia determinadas regras provenientes das academias4; o Romântico, que buscava a livre expressão dos músicos em prol da expressão dos sentimentos, representados por Bethoven, Lizt, Chopin, Wagner, dentre outros; e o Moderno e Contemporâneo que traziam as novas tendências musicais, dentre elas o nacionalismo de Villa-Lobos. Os conteúdos apresentavam-se organizados nas três séries do curso ginasial. Não há exagero de conteúdos em relação ao número de aulas semanais de canto orfeônico; por exemplo, não é cobrada do aluno grande noção teórica de música, como os estudos harmônicos ou o conceito de prosódia (que trabalha com a aplicação da palavra na música). A relação entre os conteúdos teórico-históricos da música encontrava-se em sintonia, pois é a partir da música erudita que se origina o hábito da escrita e notação musical. Vale ressaltar que é muito raro encontrar, na música popular e folclórica, músicos e compositores que tenham o costume de trabalhar com a notação musical. Na parte prática, a ênfase está no estudo dos hinos patrióticos e canções cívicas brasileiras, além de canções tradicionais estrangeiras.

Mesmo que o programa apresentasse conteúdos possíveis para aplicação prática na escola, havia por vezes uma incoerência na relação entre o currículo prescrito (oficial) com o que realmente acontecia nas escolas. As exposições da professora Ceição de Barros Barreto $(1938)^{5}$ tornam-se relevantes, uma vez que ela denunciou a relação entre o

${ }^{3}$ Entende-se por formação erudita, aquela que relaciona o estudo de técnicas e execuções vocais e instrumentais ao estudo de partituras musicais.

${ }^{4}$ Estas regras ficaram conhecidas como harmonia tradicional, que se baseava nas artes matemáticas. Assim, a música era sempre resultado de combinações lógicas do som, sendo considerado um erro harmônico, qualquer relação que não se encontrasse nas regras harmônicas. Mozart e Haydn podem ser considerados os maiores expoentes deste movimento.

${ }^{5}$ Catedrática de Canto Coral, na Escola Nacional de Música da Universidade do Brasil; ex-professora-chefe da secção de música e canto orfeônico, na Escola de Educação da Universidade do Distrito Federal. 
currículo prescrito com as práticas das escolas brasileiras:

Tudo nos leva a crer que inúmeras divergências existem entre o que os próprios programas de ensino têm estabelecido e o que realmente se pratica. Programas existem com orientação conveniente. Eles deverão, em qualquer caso, porém, ser ajustados à classe e às condições do ambiente, onde se pretenda processar o ensino. Será necessário compreender o meio, onde viva a criança, sua experiência musical anterior, seus gostos, suas preferências. Só então poder-se-á esboçar um plano de trabalho com objetivos definidos, suscetíveis de serem alcançados. Ora, isso exigirá condições de orientação do professor. Não bastará um programa. A ausência dessa verdadeira orientação observa-se geralmente na realização do ensino de música, como disciplina isolada de todas as outras. No entanto, por ser uma linguagem do sentimento ela facilmente se relaciona com todos os assuntos, prestando-se ao ensino globalizado. E só por essa forma, acreditamos que a experiência em arte e beleza possa influir na formação das crianças. (BARRETO, 1938, p. 17).

Barreto (1938) defendia que o currículo deveria ser abordado a partir da experiência musical da criança. Além disso, expunha a falta de orientação para a aplicação do currículo pelos professores de música e canto orfeônico. A falta de fontes não permite investigar a relação destes conteúdos contemplados pela legislação com os conteúdos efetivamente aplicados nos colégios secundários curitibanos.

\section{Os conteúdos de música e canto orfeônico na reforma de 1946}

O programa apresentado na Portaria n. $\stackrel{0}{300}$, de 7 de maio de 1946 não apresentava uma diferença qualitativa em relação àquele da década de 1930. Entretanto algumas diferenças em termos quantitativos merecem destaque especial para a compreensão do percurso do ensino do canto orfeônico na escola, uma vez que, além de apresentar os conteúdos adotados na legislação de 1931, ainda trazia um grande número de temas a serem trabalhados pelos professores. A Portaria $n . .0300$ de 1946 atendia aos seguintes temas:

Programas

$\mathrm{XI}$ - O programa adotado para o ensino de canto orfeônico no curso ginasial terá as seguintes unidades temáticas:

a) Elementos gráficos

b) Elementos rítmicos

c) Elementos melódicos

d) Elementos harmônicos

e) Pratica orfeônica

f) História e Apreciação Musical.

As unidades didáticas a, b, c e d deverão ser aplicadas de preferência após o exercício dos solfejos adotados.

O programa do ensino do canto orfeônico obedecerá à seguinte seriação:

$1^{\mathrm{a}}$ série

Elementos gráficos: Pauta, linhas suplementares, claves, valores, pausas, ponto de aumento e de diminuição, ligaduras, acidentes, armadura e cópias de hinos e canções a serem estudados.

Elementos rítmicos: Unidades de movimento, compasso simples, leitura métrica, ditados rítmicos fáceis, declamações rítmicas, quiálteras e anacruse.

Elementos melódicos: Intervalos, graus, escalas maiores e suas relativas, (teórica e praticamente), solfejo e ditado cantado de pequenos trechos.

Elementos harmônicos: Intervalos, harmônicos. 
Prática orfeônica: Afinação orfeônica, manossolfa simples e desenvolvimento a uma e duas vozes, canções de diversos estilos, hinos e marchas, especialmente de autores brasileiros a uma e duas vozes, efeitos de timbres diversos.

História e Apreciação musical: Finalidade do Canto Orfeônico: os orfeões e suas organizações no Brasil e no estrangeiro; palestra sôbre a música e os músicos no Brasil. Audições de discos comentados. Discernimento dos diferentes gêneros musicais.

$2^{\mathrm{a}}$ série

Elementos gráficos: Sinais de expressão, cópias de canções e hinos a serem estudados, sinais de repetição.

Elementos rítmicos: Leitura métrica, ditado rítmico, compassos compostos, síncope, declamação rítmica.

Elementos melódicos: Escalas maiores e menores (teórica e praticamente) solfejos a uma e duas vozes, ditado cantado, intervalos e suas inversões.

Elementos harmônicos: Tonalidade (teórica e praticamente) arpejos e acordes de três sons.

Prática orfeônica: Exercícios de entoação de notas cromáticas, longas, sustentadas de um pianíssimo a um fortíssimo e vice-versa; entoação da escala harmonizada por meio de processos teóricos e práticos; hinos, marchas e canções de diversos estilos, a uma, duas e três vozes.

História e Apreciação Musical: A música ameríndia, africana, portuguesa, espanhola e outras que influíram na música brasileira.

Alguns instrumentos de que se serviram os indígenas. Palestras sobre audições e concertos. Conhecimentos dos instrumentos de Banda e Orquestra. Audições de discos. Discernimento dos diferentes gêneros musicais.

$3^{a}$ série

Elementos gráficos: Cópia de canções a três e quatro vozes.

Elementos rítmicos: Leitura métrica, ditados de ritmos variados, declamação rítmica, correlação entre compassos simples e compostos, contratempo, andamento.

Elementos melódicos: Conhecimento mais completo das escalas maiores e menores (teórica e praticamente), ditados cantados, construções de frases curtas, solfejos fáceis à primeira vista a uma voz, solfejos na clave de fá na $4^{a}$ linha, intervalos cromáticos e enarmônicos, ornamentos.

Elementos harmônicos: Acordes perfeitos maiores e menores e suas inversões (teórica e praticamente), noções de tons vizinhos.

Prática orfeônica: Hinos e canções de diversos estilos a uma, duas, três e quatro vozes, manossolfa desenvolvido a duas, três e quatro vozes (diatônico e cromático). História e Apreciação Musical: Palestra sôbre a origem e a evolução da música. Folclore nacional: sua utilidade ligada à música e a história das artes. Discernimento das tonalidades maiores e menores. Audições de discos comentadas.

$4^{a}$ série

Elementos Gráficos: Cópia de canções a três e quatro vozes.

Elementos rítmicos: Leitura métrica, andamentos, metrônomo (teórico e prático), ditados rítmicos mais desenvolvidos, compassos mistos, alternados e fracionários. Elementos melódicos: Escalas cromáticas (teórica e praticamente), ornamentos; prosódia: aplicação das palavras, nas melodias, escala geral, escalas enarmônicas,

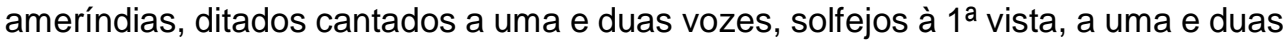
vozes.

Elementos harmônicos: Acordes de quatro sons, tons vizinhos, série harmônica. Prática orfeônica: Manossolfa desenvolvido a duas, três e quatro vozes (diatônico e cromático) hinos e canções de diversos estilos a uma, duas, três e quatro vozes. História e Apreciação Musical: Continuação das palestras sôbre a evolução da música. Folclore nacional.

Palestras sôbre a formação da Música no Brasil. Orquestra antiga, clássica e moderna. Banda e conjuntos típicos. Audições de discos comentadas.

Rio de Janeiro, em 7 de maio de 1946.

(BRASIL, 1946). 
O programa apresentado é bem completo dentro de uma formação erudita, principalmente nos estudos teóricos de música como elementos da partitura, apreciação e história da música. No entanto, ao contrário do modelo apresentado por Francisco Campos em 1931, havia uma grande gama de conteúdos para as turmas do curso ginasial. A deficiência deste programa se agravava também pelo fato de que na legislação de 1946 havia a proposta de redução no número de aulas de canto orfeônico que iria de cinco, conforme proposto na Reforma de Francisco Campos, para quatro. Com isso, os conhecimentos a serem contemplados tornavam-se inviáveis para a realidade escolar, pois, além do fato do professor atender a um grande número de turmas heterogêneas, havia o nível avançado dos conteúdos relacionados. Constava no currículo de todas as séries, a apreciação musical, teoria, solfejos, preparação dos orfeões, além de aprofundamentos sobre cada tópico. A ampliação dos conteúdos teóricos, como o estudo de harmonia e a grande quantidade de músicas a serem apreciadas, somava-se aos ensaios das canções a serem executadas, muitas vezes a quatro vozes. Isto, de certa forma, afastava o programa da realidade escolar, visto que não havia tempo hábil para a realização do trabalho e tampouco professores plenamente aptos para tal empreitada. O programa tornava-se vulnerável a apresentar problemas estruturais, pois uma deficiência de algum conteúdo em qualquer uma das séries, seja pela aprendizagem, seja pela falta de tempo para o professor vencer os conteúdos contemplados pela lei, comprometeria o aprendizado nas séries seguintes, por exemplo, seria impossível ao aluno compreender como proceder com um compasso composto, se nem mesmo conseguisse compreender um compasso simples.

Na primeira série, o aluno receberia toda a informação básica da teoria musical, dividida em elementos gráficos, elementos rítmicos, elementos melódicos, elementos harmônicos, prática orfeônica, história e apreciação musical. Mesmo que os conteúdos sejam básicos na primeira série, há uma grande quantidade de informações para o estudante. Admite-se que seria possível, para o aluno, apresentar um melhor rendimento na disciplina, desde que o estudo fosse voltado a apenas uma das áreas: história da música, teoria musical ou prática orfeônica. De maneira nenhuma estes conteúdos estão sendo desconsiderados quanto a sua importância, apenas apresenta-se o fato de que uma aula por semana seria pouco tempo para contemplar de maneira consistente e aprofundada todas estas áreas de estudo.

Além do exagero dos conteúdos, alguns tópicos tornavam-se avançados demais como, por exemplo, a prosódia oferecida à $4^{a}$ série ginasial, considerando que para 0 entendimento deste conteúdo seria necessária grande dedicação e tempo de estudo. Levase em conta o fato de que a prosódia é um veículo mais voltado para aqueles que trabalham com composição, sendo assim, não tão importante para uma formação musical básica em que os alunos recebiam as canções prontas nas partituras. $\mathrm{Na}$ segunda série, dentro do tópico História e Apreciação Musical, o programa apresenta uma enorme quantidade de músicas a serem apreciadas pelos alunos: ameríndia, africana, portuguesa, espanhola e outras que influíram na música brasileira. Apesar deste ser um conhecimento importante, seriam necessárias várias aulas para que o professor contextualizasse e apreciasse junto aos alunos todas estas músicas que, por serem características das mais variadas regiões, apresentavam elementos diferenciados da estética ocidental como, diferentes instrumentos e tonalidades, diferentes lógicas musicais, diferentes melodias e etc. Com isso, tornava-se 
difícil para o aluno assimilar todas estas informações, além do conhecimento elementar de notação musical, prática de canto e história da música.

$\mathrm{Na}$ parte prática dos conteúdos, encontra-se o mesmo problema. Para que os alunos apresentassem uma execução satisfatória das canções, por mais simples que elas fossem, tornavam-se necessários vários ensaios, que preferencialmente deveriam seguir uma rotina que propiciasse aprender o canto e adquirir confiança de cantar em grupo. A grande quantidade de conteúdos teóricos, possivelmente, interferia no ritmo dos ensaios, uma vez que havia apenas 50 minutos semanais destinadas as aulas de canto orfeônico. Levanta-se a possibilidade da falta de adequação do tempo com o conteúdo, pois se por um lado o programa é bem completo, por outro, encontra-se deslocado da realidade escolar, já que não levava em consideração os imprevistos em sala, como talvez, a dificuldade no aprendizado, que no caso, levaria o professor a reforçar um conteúdo, impedindo o desenvolvimento do programa, tornando impossível ao educador lidar, por exemplo, com arpejos e acordes de sons (elementos harmônicos da $2^{\underline{a}}$ série), sem antes ter feito um trabalho consistente com elementos melódicos, tais como intervalos, escalas, graus. Mesmo considerando a possível organização do professor para a divisão temporal da teoria e da prática em suas aulas, os ensaios teriam ritmos incertos, o que faria necessário relembrar e retomar as canções já ensaiadas anteriormente. O mesmo acontecia nos estudos teóricos de música.

$\mathrm{Na} 3^{\text {a }}$ série, encontram-se canções desenvolvidas a quatro vozes, que são de difícil execução e necessitam de um trabalho prático inicial bem efetuado, uma vez que era imprescindível uma certa experiência de práticas vocais para o desempenho destas canções. A performance das canções a quatro vozes requer uma grande capacidade de sensibilidade musical dos estudantes, para que percebam todas as linhas melódicas do coro, sem se atrapalhar com as suas próprias. Outro problema é a leitura à 1a vista: para executar este tipo de tarefa, o aluno devia ter um preparo e um treinamento prévio. Não seria apenas com uma aula semanal, após três anos de curso, que o aluno conseguiria executar esta tarefa. Para isto eram necessários um estudo mais aprofundado e uma certa dedicação extra-classe por parte destes educandos. Enfim, percebe-se no programa da disciplina, uma exigência avançada nos conteúdos, sendo que, se os alunos realmente adquirissem todo o conhecimento contemplado neste currículo, já teriam capacidade total de trabalhar com qualquer partitura musical. Conclui-se que esta proposta de conteúdos para o curso ginasial apresentava-se muito avançada para um curso que visava apenas uma formação básica. As próprias finalidades do ensino secundário em vigor não contemplavam esta educação tão avançada, já que havia uma ênfase na formação da "personalidade integral dos adolescentes" e na elevação da "consciência patriótica e a consciência humanística". (BRASIL, 1942).

No livro Aulas de canto orfeônico para as quatro séries do curso ginasial, que mesmo publicado em 1958, seguia as orientações da legislação de 1946, Judith Morrison Almeida apresentou os conteúdos para o canto orfeônico baseado no programa acima citado:

Pauta / Nota / Clave / Valores / Figuras / Elementos essenciais da música/ Compasso / Quadro de compassos / Origem dos indicadores do compasso / Pausa 
/ Ponto / Quiálteras / Acidentes / Escalas / Mano-solfa / Síncope / Diapasão / Metrônomo

SEGUNDA PARTE

CULTURA GERAL

Finalidades do canto orfeônico / Califasia, Califonia, Declamação rítmica, Hino Nacional (histórico) / Origem dos valores das notas / Valor educativo do canto coral/ Influência da música ameríndia / Influência do africano / Folclore / Instrumentos musicais primitivos / Instrumentos de orquestras e bandas / Conjuntos orquestrais / Algumas formas musicais / Instrumentos que fazem parte da orquestra sinfônica moderna / A Música (o que é a sua influência) / Pequena História da Música.

\section{TERCEIRA PARTE}

BIOGRAFIAS

Palestina / Bach (João Sebastião) / Handel / Haydn / Mozart / Beethoven / Chopin / Liszt / Debussy / Ravel / Tchaikovsky / Rimsky-Korsakof / Os "Cinco Russos";

Brasileiros: Francisco Manuel da Silva/ Francisco Braga / Leopoldo Miguez / D. Pedro I / Padre José Maurício / Carlos Gomes / Alberto Nepomuceno / Barroso Netto / Henrique Oswald / João Gomes Júnior / Vila Lobos / Oscar Lorenzo Fernandes / Luciano Gallet.

\section{QUARTA PARTE \\ PRÁTICA}

Exercícios aplicados graduados / Solfejos graduados para todas as séries.

Hinos: Hino Nacional Brasileiro / Hino à Bandeira Nacional / Hino à Independência/ Hino da Proclamação da República / Hino 7 de Setembro / Hino à Vitória / Hino Acadêmico

Canções Cívicas: Canção do Marinheiro / Brasil Unido / Bandeira do Brasil / Trabalhar, Progredir e Vencer / Canção do Brasil / Desfile aos heróis do Brasil;

Cânones

Canções a uma e duas vozes: Luar do Sertão / Anoitecer / O reloginho / O tamborzinho / As árvores e as aves / Ave Maria / Terra Natal / Barcarola / Sinais de expressão.

(ALMEIDA, 1958, p. 111-112).

Dividido em grandes áreas do estudo musical (Teoria Musical, Cultura Geral, Biografias e Prática), o livro contemplava os pontos apresentados no programa de 1946. Os conteúdos relativos à música erudita aparecem em grande escala, principalmente na terceira parte do livro, que era dedicada às biografias de músicos eruditos brasileiros e estrangeiros. Apesar da ênfase dada à música erudita, havia por parte de Villa-Lobos e de outros artistas do movimento Modernista ${ }^{6}$, como Mário de Andrade e Oswald de Andrade, uma busca do resgate cultural do Brasil, por meio das manifestações folclóricas brasileiras. Segundo Gramsci (1978), definir música folclórica seria muito difícil, uma vez que:

As artes menores foram sempre ligadas às artes maiores e dependeram delas. Assim, o folclore sempre esteve ligado à cultura da classe dominante e, a seu modo, extraiu dela motivos que se inseriam nele em combinação com as tradições precedentes. (GRAMSCI, 1978, p. 189).

Desta forma, nota-se uma circularidade cultural entre a arte da elite e a arte do povo, sendo que ambas estão intimamente interligadas e são interdependentes. Villa-Lobos defendia a música folclórica, porém uma parcela da música popular sofria com a ação do

\footnotetext{
${ }^{6}$ Surgido em 1922, na Semana de Arte, o movimento Modernista reuniu artistas das mais variadas áreas que se empenhavam em divulgar a arte nativa brasileira, cultura indígena e folclórica: Tarsila do Amaral, Anita Malfati e Di Cavalcanti na pintura; Mário de Andrade, Oswald de Andrade e Manuel Bandeira na Literatura, e outros, que também estiveram empenhados no "resgate" da cultura brasileira.
} 
DIP (Departamento de Imprensa e Propaganda) no Governo de Getúlio Vargas. O programa não compreendia a música que era produzida e ouvida pelo povo, pois desde o advento do rádio, em 1922, criou-se uma cultura de massa no país, no qual a canção popular mantinha grande destaque, como era o caso dos cantores de vozes de estilo operístico, como Augusto Calheiros, Francisco Alves, Vicente Celestino, Orlando Silva e Sílvio Caldas. (CALDAS, 1989).

Havia uma preocupação em distinguir o que era a boa música e o que era a música manipulada pelos meios de comunicação. Sevcenko (1999), em sua obra Literatura como missão, apresenta um outro indício que inibia a música boêmia, caso da perseguição ao violão durante as duas primeiras décadas do século XX, na cidade do Rio de Janeiro:

\begin{abstract}
Modelando-se essa sociedade, como seria de se esperar, por um critério utilitário de relacionamento social, não é de se admirar a condenação veemente a que ela submete também certos comportamentos tradicionais, que aparecem como desviados diante do novo parâmetro, como a serenata e a boemia. A reação contra a serenata e a boemia. A reação contra a serenata é centrada no instrumento que a simboliza: o violão. Sendo por excelência o instrumento popular, o acompanhante indispensável das modinhas e presença constante nas rodas de estudantes boêmios, o violão passou a significar, por si só, um sinônimo de vadiagem. Daí a imprensa incitar a perseguição policial contra o seresteiro em particular e o violão em geral. (SEVCENKO, 1999, p. 32).
\end{abstract}

Mesmo que Villa-Lobos não tivesse apresentado ressalvas contra o violão, até mesmo porque realizou diversas peças para o instrumento, o maestro demonstrava suas considerações sobre a música produzida pelos seresteiros. Na apresentação da obra Noção de Música e Canto Orfeônico, de Freitas e Teitel (1941), o maestro Villa-Lobos relatava sua posição frente a uma parte da cultura popular:

\begin{abstract}
A música no Brasil até anos passados foi sempre considerada como agradável passatempo, pretexto (sic) para a loucura das gritarias carnavalescas, elemento obrigatório para as danças sociais, meio fisiológico para o desabafo dos seresteiros, motivo indispensável para as temporadas oficiais, de reuniões mundanas nos teatros e salões elegantes, fator rítmico para puxar tropas, etc., e raramente cultivada com fins exclusivamente artísticos. (VILLA-LOBOS apud FREITAS; TEITEL, 1941, p. 3).
\end{abstract}

Nota-se que nem toda a música brasileira era considerada como merecedora de respeito no âmbito nacional. Isso ocorria devido a muitos fatores como a letra, o ritmo e até mesmo, a postura do músico perante a sociedade. Além disso, havia um grupo intelectualizado que ainda resistia fortemente à música popular. Desta forma, o pensamento de Villa-Lobos apresenta uma ligação com o pensamento de toda uma elite cultural. Essa crítica a música popular, não foi exclusiva apenas no Brasil, uma vez que na Europa surgiam fortes tendências a criticar a música de caráter comercial. Um filósofo que discutiu os problemas da invasão de uma indústria cultural foi Adorno (1974), pertencente ao grupo de filósofos da Escola de Frankfurt. Para ele:

Somente na era do cinema sonoro, do rádio e das formas musicais de propaganda, a música ficou, precisamente em sua irracionalidade, inteiramente seqüestrada pela ratio comercial. Mas assim que a administração industrial de todo o patrimônio cultural se faz totalitária, ela adquire ainda poder sobre tudo o que não admite conciliação do ponto de vista estético. Com o poder dos mecanismos de distribuição de que dispõem o mau gosto e os bens culturais já ultrapassados e com a 
predisposição dos ouvintes determinada num processo social, a música radical caiu, durante $o$ industrialismo tardio, num completo isolamento. Para os autores que querem viver, este é o pretexto moral e social para uma falsa paz. Forma-se assim um tipo de estilo musical que, por mais que proclame a pretensão irrenunciável do moderno e do sério, se assimila à cultura das massas em virtude de uma calculada imbecibilidade. (ADORNO, 1974, p. 15).

Adorno era radical em sua postura. Representante de um grupo altamente intelectualizado e apreciador de música erudita, Adorno reagiu contra a banalização causada pelos meios de comunicação em massa. Relatava que a música radical perdia seu espaço referindo-se, evidentemente, à música erudita do século $\mathrm{XX}$, como a daqueles eleitos na sua obra Filosofia da nova música: Schoenberg e Stravinski.

$\mathrm{Na}$ quarta parte do livro de Judith Morrison de Almeida, eram contempladas as canções a serem executadas pelos orfeões. Aqui se podem destacar alguns pontos relevantes. Primeiro, a distinção da relação entre teoria e prática, pois estas eram tratadas como se fossem duas disciplinas separadas, contendo cada uma sua própria avaliação. A segunda questão trata da temática, uma vez que a grande maioria das canções ou eram hinos ou eram canções cívicas. Estas canções estavam sempre entre as primeiras lições de canto orfeônico. A todo o cidadão era necessário cantar, conhecer e saber se portar na execução do Hino Nacional, conhecendo suas obrigações, assim como as suas proibições, conforme expõe o decreto-lei n. 4.545 de 31 de Julho de 1942:

\section{CAPÍTULO VII}

Art. 34ํ- É obrigatório o ensino do desenho da Bandeira Nacional e do canto do Hino Nacional em todos os estabelecimentos, públicos ou particulares, de ensino primário, normal, secundário e profissional.

Art. $39^{\circ}$ - Ninguém poderá ser admitido ao serviço público sem que demonstre conhecimento do Hino Nacional.

(BRASIL, 1942).

Esta obrigação escolar de ensinar o Hino aos alunos ficou sob a responsabilidade do professor de canto orfeônico. A premissa básica deste ensino era fazer com que o aluno tivesse condições de conhecer a letra, a melodia e a harmonia dos principais hinos pátrios. Isto pode ser observado nas próprias palavras de Villa-Lobos:

[...] têm-se realizado anualmente demonstrações orfeônicas de caráter cívico para comemorar as grandes datas da Pátria, com cânticos que a exaltam a significação própria do dia que se celebra, como o da Bandeira, o da Independência, o do PanAmericanismo, assim como outras datas de significação nacional. [...] Convém lembrar, nesta altura, que num livro oficial sôbre o programa do ensino de música nas escolas da Prefeitura da Capital Federal, publicado em 1937, fiz constar a seguinte observação: 'As festas e concentrações escolares, com exceção das imprescindíveis, dentro da orientação do programa do ensino de música traçado, e previstas de acôrdo com a organização de cada escola, só poderão acarretar prejuízo, não somente quanto à aplicação normal do ensino de música, mas também a outras disciplinas'. (VILLA-LOBOS, 1946, p. 514).

O discurso de Villa-Lobos privilegiava as datas que deveriam ser comemoradas com apresentações orfeônicas: o Dia da Bandeira e o Dia da Independência, como fez o maestro nas demonstrações realizadas entre 1935 e 1940 no estádio Vasco da Gama, que contaram com um total entre 30.000 e 40.000 mil vozes. Villa-Lobos alertava, porém, que o excesso de apresentações seria prejudicial ao trabalho, não só da disciplina musical, 
como das outras disciplinas visto que a preparação do evento e do grupo para as apresentações reduziria ainda mais o tempo de aula de canto orfeônico, que já era demasiadamente curto dentro dos currículos escolares. Nota-se também que há a preocupação da concorrência do canto orfeônico com outras disciplinas, uma vez que a dedicação dos alunos para as apresentações poderia comprometer a evolução dos conteúdos das cadeiras científicas. Villa-Lobos claramente se preocupava com uma das maiores premissas para o ensino de música, que era a formação da sensibilidade e o bom gosto musical. Assim, Villa-lobos possivelmente entendia o prejuízo à disciplina se esta estivesse voltada apenas para promoção de tais apresentações, pois desta forma o ensino de música voltaria a ser, segundo Fernando de Azevedo (1958), como era o ensino de música nas escolas tradicionais, nas quais as crianças cantavam sem nenhum senso estético, para participarem de apresentações escolares que serviam apenas de vitrine para deleite dos pais.

Nota-se nas canções contempladas no livro didático de Almeida que excluindo os hinos, ainda sobravam as canções cívicas que apresentavam temas que deveriam contemplar ensinamentos de moral e de convivência na sociedade. Isso pode ser observado em músicas como Trabalhar, Progredir e Vencer, que apresenta a importância do trabalho para os alunos. Tal fato assumia uma relação com a política getulista do DIP (Departamento de Imprensa e Propaganda), que proibia a execução pública de determinadas músicas que falassem de temas como a exaltação à vadiagem e à vida boêmia. Este exemplo pode ser observado com as proibições do DIP à música de Wilson Batista, durante a década de 1930, em São Paulo, por enaltecer ideologias antitrabalhistas ${ }^{7}$.

Se de um lado, aparecem os conteúdos prescritos para o ensino de canto orfeônico, por outro, aparecem as avaliações, que de certa forma legitimam os conteúdos abrangidos no cotidiano escolar. A seguir será discutida a relação entre os conteúdos oficiais e os conteúdos das provas encontradas no Colégio Estadual do Paraná em 1946 e 1947. Essas avaliações práticas eram divididas em 10 ou 20 pontos, sendo que para cada ponto havia um conteúdo. Ao professor cabia sortear um dos pontos e avaliar os alunos sobre 0 conteúdo escolhido. Mesmo assim, era comum que os mesmos tópicos estivessem inseridos em dois ou três pontos, não necessitando ao professor inserir nestas provas os 10 ou 20 conteúdos diferentes. A avaliação mais antiga encontrada é datada do $2^{\circ}$ Semestre de 1946. Não foram achados vestígios de avaliações antes disso, o que leva a crer que o Ginásio Paranaense, como colégio modelo, acatou a lei e a pôs em prática ainda no ano de 1946. Na lista de pontos da segunda prova parcial de canto orfeônico da $1^{\text {a }}$ série (avaliação prática em quartetos), realizada no dia 23 de Novembro, estão contemplados os seguintes conteúdos:

1 - Hino da Independência: escala e exercício / 2 - Hino da Proclamação da República: escala e exercício / 3 - Canção do Soldado: escala e exercício / 4 - Pátria Minha: escala e exercício / 5 - Canção do Expedicionário: escala e exercício / 6 -

\footnotetext{
${ }^{7}$ Em 1933, com seu samba intitulado Lenço no Pescoço, Wilson Batista, contemplava a malandragem e o ócio, sendo perseguido pelo DIP. Segue um trecho da letra: "Eu passo gingando / Provoco e desafio / Eu tenho orgulho / Em ser tão vadio / Sei que eles falam / Deste meu proceder / Eu vejo quem trabalha / Andar no misere". Em 1940, em plena vigência da política repressiva do Estado Novo, Wilson Batista, junto com Ataulfo Alves compõe o samba O Bonde de São Januário, uma exaltação ao trabalhismo, em que se mostra arrependido pela vida boêmia: "Antigamente eu não tinha juízo / Mas resolvi garantir meu futuro / Veja você / Sou feliz, vivo muito bem / A boêmia não dá camisa a ninguém". (CALDAS, 1995).
} 
Canção do Estudante: escala e exercício / 7 - Deus Salve a América: escala e exercício/ 8 - Hino Nacional: escala e exercício / 9 - Hino à Bandeira: escala e exercício/ 10 - Hino da Proclamação da República: escala e exercício / 11 - Canção do Soldado: escala e exercício / 12 - Pátria Minha: escala e exercício / 13 - Canção do Expedicionário: escala e exercício / 14 - Canção do Estudante: escala e exercício / 15 - Deus Salve a América: escala e exercício / 16 - Hino Nacional: escala e exercício / 17 - Canções Regionais: escala e exercício / 18 - Hino Nacional: escala e exercício / 19 - Hino à Bandeira / 20 - Hino da Independência ${ }^{8}$. (COLÉGIO ESTADUAL DO PARANÁ, 1946).

Alguns comentários sobre esta avaliação tornam-se pertinentes. Em primeiro lugar, vale destacar que os temas são os mesmos para as quatro séries ginasiais, sendo basicamente hinos pátrios e canções cívicas, o que comprovaria a falta de progressão das músicas utilizadas nas aulas de canto orfeônico. Nota-se também que apenas as Canções Regionais não contemplavam o caráter cívico. Na prova prática, nota-se a forte presença do caráter nacionalista e praticamente nenhuma referência às canções de diversos estilos como previa o programa oficial da disciplina na legislação de 1946, ou mesmo as canções folclóricas, defendidas por Fernando de Azevedo e Heitor Villa-Lobos ainda na década de 1920.

O conteúdo nacionalista cumpria uma importante função educacional para um país que buscava uma afirmação enquanto nação. No entanto, as canções tipicamente brasileiras, entre elas os temas folclóricos e indígenas, assumiam outro conhecimento indispensável para a disciplina. Esta discussão, porém, não se estendeu na escola com a mesma força do que nos discursos de Heitor Villa-Lobos. Por outro lado, havia uma ênfase no ensino de teoria musical que era visto como um poderoso atributo para a elevação cultural dos estudantes secundaristas. Na primeira avaliação parcial de 1947, que dispõe de apenas 10 pontos também idênticos para as turmas de $1^{\underline{a}}$ a $4^{\underline{a}}$ série do ginasial, há uma diferente relação daqueles do ano de 1946, pois se encontra ênfase nas questões teóricas da disciplina. A partir da segunda avaliação, os conteúdos das diferentes séries se modificam, conforme se nota nas listas de pontos para a segunda prova parcial de Canto do Colégio Estadual do Paraná:

$1 \stackrel{\text { a }}{\text { série do curso ginasial }}$

Pontos: a) Seus nomes; b) Seus valores; Da pauta natural; Linhas suplementares; Clave de sól; Ponto de aumento; Ponto de diminuição; Ligadura; Acidentes; Figuras das notas; Função dos sinais de alteração; Armadura; Colocação dos sostenidos; Colocação dos bemóis; Compassos simples; Função da letra $\mathrm{C}$ representando o compasso; Unidade de tempo; Valor que representa a unidade de tempo; Pausas; Cópia - Uma melodia. Sorteado: Colocação dos sostenidos.

$2^{\mathrm{a}}$ série do curso ginasial

Pontos: Escala do modo maior; Escala do modo menor; Intervalos simples e compostos; Inversão de intervalos; Classificação de intervalos; a) Pela distância em tons; b) Pela distância em tons; Compassos simples; Compassos compostos; Maneira de encontrar o composto de um compasso simples e vice-versa; Instrumentos de banda; Instrumentos de orquestra; Sinais de repetição; Acordes de 3 sons; Sua disposição; a) no estado fundamental; b) Na $1^{\underline{a}}$ inversão; c) $\mathrm{Na} 2^{\underline{a}}$ inversão; Tonalidade; Cópia. Sorteado: Inversão.

${ }^{8}$ Devido à necessidade de conter 20 opções para sorteio, alguns dos pontos considerados mais importantes poderiam ser repetidos. 
$3^{\mathrm{a}}$ série do ginasial

Pontos: Andamento; Contra-tempo; Escalas maiores; Escalas menores; Clave de fá na 4⿳亠丷厂 linha; Intervalos cromáticos; Intervalos enarmônicos; Ornamentos; Acorde perfeito maior; Acorde perfeito menor; Disposição de acordes de 3 sons; a) No estado fundamental; b) $\mathrm{Na} 1^{\underline{a}}$ inversão; c) $\mathrm{Na} 2^{\underline{a}}$ inversão; Tons vizinhos; Tons relativos; Acorde perfeito maior e menor; Graus em que os mesmos se encontram na escala de Dó maior; Acorde de 5a diminuição; Cópia. Sorteado: Graus em que os mesmos (acorde perfeito maior e menor) se encontram na escala de Dó maior.

\section{$4^{\mathrm{a}}$ série ginasial}

Pontos: Correlação entre compassos simples e compostos; Contra-tempo; Escalas maiores; Andamento; Estrutura de escala maior; Estrutura de escala menor harmonica; Estrutura de escala menor melodica; Escala cromatica de modo maior; Escala cromatica de modo menor; Sons enarmônicos; Escalas enarmônicas; Acordes de 4 sons; Disposição d'estes acordes; a) no estado fundamental; b) Na $1^{\text {a }}$ inversão; c) Na $2^{2}$ inversão; $\mathrm{Na} 3^{\underline{a}}$ inversão; Gráus sobre que se encontram os acordes perfeito maior e perfeito menor; a) $\mathrm{Na}$ escala do modo maior b) $\mathrm{Na}$ escala do modo menor; Cópia. Sorteado: Acordes de 4 sons.

(COLÉGIO ESTADUAL DO PARANÁ, 1947).

Nota-se agora uma progressão lógica dos conteúdos. Nos dois primeiros anos era trabalhada a iniciação musical (intervalos, figuras, compassos simples, clave de sol, entre outras) e a partir da 3a e 4⿳亠丷a séries surgiam conteúdos de um nível mais avançado, tais como clave de fá, tons vizinhos e acordes de 5a (na 3a série), e escala cromática e acordes de quatro sons (na $4^{\mathrm{a}}$ série). Os conteúdos teóricos encontrados nesta prova são muito mais acessíveis aos alunos do que aqueles apresentados no programa de música na legislação de 1946, que continham ditados rítmicos, solfejos a primeira vista (inclusive em duas vozes), escalas ameríndias, prosódia, entre outros. Vale ressaltar também que nenhuma das provas encontradas nos arquivos do Colégio Estadual do Paraná avaliava a história da música estrangeira ou nacional.

\section{Considerações finais}

Pode-se notar, em suma, alguns tópicos importantes sobre os conteúdos de música e canto orfeônico no ensino ginasial. Em primeiro, o conteúdo nacionalista que assumia um importante papel para um país que buscava uma afirmação enquanto nação. Neste sentido, a interpretação de hinos e canções que valorizassem a Pátria era de maneira geral, um dos principais objetivos da disciplina. No entanto, as canções tipicamente brasileiras, entre elas as canções folclóricas e indígenas assumiam outro conhecimento indispensável para a disciplina. Esta discussão, porém, não se estendeu na escola com a mesma força do que nos discursos de Heitor Villa-Lobos. Por outro lado, havia uma ênfase no ensino de teoria musical, que se tornava um poderoso atributo para a elevação cultural dos estudantes secundaristas.

A legislação de 1931 mostrava um programa muito mais coerente do que aquele apresentado em 1946, que adicionava uma grande quantidade de assuntos, trazendo como conseqüência uma contradição entre os conteúdos propostos pela lei e a prática efetivamente aplicada no Colégio Estadual do Paraná. Não foi encontrada nenhuma divergência ideológica entre o conteúdo previsto e o conteúdo adotado, mas sim, uma adaptação natural dos conteúdos para a realidade escolar vigente, que além das dificuldades naturais de assimilação dos conhecimentos em turmas heterogêneas, ainda contava com um número reduzido de aulas semanais. 


\section{Referências}

ADORNO, Theodor. Filosofia da nova música. São Paulo: Perspectiva, 1974.

ALMEIDA, Judith Morrison. Aulas de canto orfeônico para as quatro séries do Curso Ginasial. São Paulo: Companhia Editora Nacional, 1958.

AZEVEDO, Fernando de. Novos caminhos e novos fins: a nova política da educação no Brasil. Subsídios para uma história de quatro anos. São Paulo: Melhoramentos, 1958.

BARRETO, Ceição de Barros. Côro orfeão. São Paulo: Companhia Melhoramentos, 1938.

BRASIL. Decreto-Lei n. ⒚890, de 18 de abril de 1931. Diário Oficial da União. 01 de maio de 1931, p. 6945.

. Decreto-lei n.o 4.244, de 9 de abril de 1942. Diário Oficial da União. Seção 1. 10 de abril de 1942.

Decreto-lei n. 4.545 de 31 de Julho de 1942. Diário Oficial da União. 9 de setembro de 1942.

1946.

Portaria n. 300 , de 7 de maio de 1946. Diário Oficial da União. 14 de maio de

CALDAS, Waldenyr. Iniciação à música popular brasileira. São Paulo: Ática, 1989.

Luz Neon: canção e cultura na cidade. São Paulo: Studio Nobel, SESC, 1995.

CHERVEL, André. História das disciplinas escolares: reflexões sobre um campo de pesquisa. Teoria \& Educação, Porto Alegre, Pannonica, n. 2, p. 177-229, 1990.

COLÉGIO ESTADUAL DO PARANÁ. Relatório de Novembro/Dezembro de 1946 do Curso Ginasial. Curitiba, 1946.

Relatórios dos meses de Abril, Maio e Junho de 1947 do Curso Ginasial e Colegial. Curitiba, 1947.

Relatórios dos meses de Janeiro, Fevereiro, Março de 1947 (1ํVolume) do

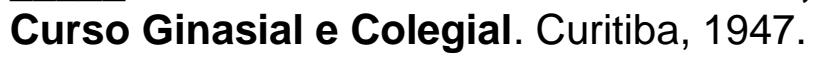

Relatórios dos meses de Outubro, Novembro e Dezembro de 1947 do Curso Ginasial e Colegial. Curitiba, 1947.

CONTIER, Arnaldo Daraya. Passarinhada do Brasil: canto orfeônico, educação e getulismo. Bauru: EDUSC, 1998.

FONTERRADA, Marisa Trench de Oliveira. De tramas e fios: um ensaio sobre música e educação. 2 ed. São Paulo: UNESP, 2008.

FREITAS, Maria Elisa Leite; TEITEL, Samuel. Noções de música e canto orfeônico: $1^{\text {a }}$ série. Papelaria, 1941.

FUKS, Rosa. O Discurso do Silêncio. Rio de Janeiro: Enelibros, 1991.

GALINARI, Melliandro Mendes. A Era Vargas no pentagrama: dimensões políticodiscursivas do canto orfeônico de Villa-Lobos. 2007. 368 f. Tese (Doutorado) - Programa de Pós-Graduação em Estudos Lingüísticos, Faculdade de Letras, Universidade Federal de Minas Gerais, Belo Horizonte, 2007.

GILIOLI, Renato de Souza Porto. “Civilizando” pela música: a pedagogia do Canto Orfeônico na escola paulista da primeira república (1910-1930). 2003. 279 f. Dissertação (Mestrado) - Programa de Pós-Graduação em Educação, Faculdade de Educação, Universidade de São Paulo, 2003. 
Educação musical antes e depois de Villa-Lobos e os registros sonoros de uma época. Programa nacional de apoio à pesquisa. Fundação Biblioteca Nacional: Ministério da Cultura, 2008.

GRAMSCI, Antonio. Literatura e vida nacional. Rio de Janeiro: Civilização Brasileira, 1978.

LOUREIRO, Alícia Maria Almeida. 0 ensino de música na escola fundamental. 4 ed. Campinas: Papirus, 2003.

SEVCENKO, Nicolau. Literatura como missão: tensões sociais e criação cultural na primeira república. São Paulo: Brasiliense, 1999.

VILLA-LOBOS, Heitor. Educação musical. Boletim Latino Americano de Música, Rio de Janeiro, v. I/6, p. 515-588, abr. 1946.

WILSON LEMOS JÚNIOR é Doutor em Educação pela PUC-PR (Pontifícia Universidade Católica do Paraná), professor no IFPR (Instituto Federal do Paraná - Campus Curitiba) e no Programa de Pós-Graduação em Educação Profissional e Tecnológica em Rede Nacional (ProfEPT), IFPR - Campus Curitiba.

Endereço: Rua Vereador Jurandir de Azevedo e Silva, 180, sobrado 5 - Barreirinha - 82700300 - Curitiba/PR - Brasil.

E-mail: juniorlem@gmail.com

Recebido em 19 de janeiro de 2017.

Aceito em 20 de abril de 2017. 